\title{
Systematic review of the safety and efficacy of tramadol during office hysteroscopy
}

\section{Ofis histeroskopi sırasında tramadolün güvenlik ve etkinliğinin sistematik derlemesi}

\author{
(1) Hiba Maarouf ${ }^{1}$, (1) Greg J. Marchand ${ }^{2}$, (1) Kelly Ware ${ }^{2}$, (1) Ahmed Masoud ${ }^{3}$, (1) Alexa King², (1) Stacy Ruther ${ }^{2}$, \\ (D) Giovanna Brazil², (1) Hollie Ulibarri², (1) Julia Parise², (1) Amanda Arroyo², (1) Katelyn Sainz², \\ (1) Mohammad Abrar Shareef ${ }^{4}$
}

${ }_{1}^{1}$ REProVita Fertility Center, Recklinghausen, Germany

2Marchand Institute for Minimally Invasive Surgery, Mesa, Arizona, USA

${ }^{3}$ Fayoum University Faculty of Medicine, Fayoum, Egypt

${ }^{4}$ Sebasticook Valley Hospital, Clinic of Internal Medicine, Pittsfield, Maine, USA

\begin{abstract}
Office hysteroscopy $(\mathrm{OH})$ is a common procedure in gynecology. Pain is the most frequently reported problem in OH. In this study, we aimed to investigate the role of tramadol administration in relieving pain in women undergoing OH. We searched PubMed, the Cochrane Library, ClinicalTrials.gov, MEDLINE, Scopus, and Web of Science databases for relevant clinical trials based on our search terms. We included randomized controlled trials and included all published trials in all six searched databases from their inception until February $28^{\text {th }} 2021$.

We included pain as the primary outcome, and the incidence of adverse events of tramadol as secondary outcomes. We performed the analysis of continuous data using mean difference (MD) and dichotomous data using risk ratio (RR). We found that tramadol led to significantly less pain during the actual procedure $[\mathrm{MD}=-1.27,95 \%$ confidence interval $(\mathrm{CI}):(-1.66,-0.88) ; \mathrm{p}<0.001]$, immediately after the procedure [MD=-1.03, 95\% CI: $(-1.40,-0.67)$; $\mathrm{p}<0.001]$, and 30 minutes after the procedure [MD=-0.74, 95\% CI: (-1.06, -0.41); p<0.001]. Regarding safety endpoints, no significant difference was noted for dizziness [RR=1.88, 95\% CI: $(0.79,4.47) ; \mathrm{p}=0.16]$ or vomiting [RR=1.80, $95 \% \mathrm{CI}:(0.40,8.18) ; \mathrm{p}=0.45]$. Based on the available data, we conclude that tramadol administration seems to be both effective and safe for patients undergoing office hysteroscopy.
\end{abstract}

Keywords: Office hysteroscopy, tramadol, office surgery, ERAS protocol, ERAS hysteroscopy

$\mathrm{O} z$

Ofis histeroskopi $(\mathrm{OH})$ jinekolojide yaygın bir prosedürdür. $\mathrm{OH}$ için en sık bildirilen komplikasyon ağrıdır. Bu çalışmada, OH uygulanan kadınlarda ağrının giderilmesinde tramadol uygulamasının rolünü araştırmayı amaçladık. Arama terimlerimize dayalı olarak ilgili klinik çalışmalar için PubMed, Cochrane Library, ClinicalTrials.gov, MEDLINE, Scopus ve Web of Science veritabanlarında tarama yaptık. Derlemeye randomize kontrollü çalışmaları dahil ettik. Tarama yaptığımız 6 veri tabanındaki yayınlanmış tüm çalışmalar, başlangıçlarından 28 Şubat 2021 'e kadar dahil edildi. Ağrıyı birincil sonlanım ve tramadolün advers olaylarının insidansını ikincil sonlanım olarak kabul ettik. Sürekli verilerin analizini ortalama farkı (MD) kullanarak; ikili verilerin analizini risk oranını (RO) kullanarak gerçekleştirdik. Tramadolün gerçek prosedür sırasında önemli ölçüde daha az ağriya neden olduğunu bulduk [MD=$1,27 \% 95$ güven aralığ $(G A)=(-1,66,-0,88) \mathrm{p}<0,001]$, işlemden hemen sonra [MD=-1,03\%95 $\mathrm{GA}=(-1,40,-0,67) \mathrm{p}<0,001]$ ve prosedürden 30 dakika sonra $[\mathrm{MD}=-0,74 \% 95 \mathrm{GA}=(-1,06,-0,41) \mathrm{p}<0,001]$. Güvenlik sonlanım noktaları ile ilgili olarak, baş dönmesi $[\mathrm{RO}=1,88(\% 95 \mathrm{GA}=0,79,4,47) \mathrm{p}=0,16]$ veya kusma $[\mathrm{RO}=1,80 \% 95 \mathrm{GA}=(0,40,8,18) \mathrm{p}=0,45]$ açısından anlamlı bir fark kaydedilmedi. Mevcut verilere dayanarak, tramadol uygulamasının OH yapılan hastalar için hem etkili hem de güvenli olduğu sonucuna vardık.

Anahtar Kelimeler: Ofis histeroskopi, tramadol, ofis cerrahisi, ERAS protokolü, ERAS histeroskopi

\section{Introduction}

Hysteroscopy is considered the gold standard investigation for the evaluation of uterine abnormalities ${ }^{(1-3)}$. One very useful variant of this is office hysteroscopy $(\mathrm{OH})$, where minimally invasive tools are used alongside local anesthesia to perform hysteroscopy in the office setting. Like traditional hysteroscopy with general anesthesia, $\mathrm{OH}$ involves visualization of the cervical

Address for Correspondence/Yazışma Adresi: Greg J. Marchand MD,

Marchand Institute for Minimally Invasive Surgery, Mesa, Arizona, USA

Phone: +4806280566 E-mail: gm@marchandinstitute.org ORCID ID: orcid.org/0000-0003-4724-9148

Received/Geliș Tarihi: 03.04.2021 Accepted/Kabul Tarihi: 07.05.2021

${ }^{\oplus}$ Copyright 2021 by Turkish Society of Obstetrics and Gynecology

Turkish Journal of Obstetrics and Gynecology published by Galenos Publishing House 
canal, uterine cavity, endometrium, and the origin of the fallopian tubes via a miniaturized endoscope that is introduced directly through the cervix without the need for dilation. A uterine distending medium, usually saline, is continuously pumped into the uterine cavity during the procedure to maintain distension ${ }^{(4)}$. The main two types of hysteroscopes include rigid and flexible. The rigid type consists of an optic channel (contprocaining a camera and optical prisms) and an outer sheath that allows entry and return of the fluid used in the examination. The second type is the flexible hysteroscope that consists of a system of optical fibers and a flexible sheath. Many authors have reported flexible hysteroscopes to be associated with less pain ${ }^{(5,6)}$.

$\mathrm{OH}$ is indicated in diagnostic cases and can be therapeutic such as in resection of fibroma or polyp. The main indications for this investigation include menstrual cycle abnormalities such as menorrhagia or metrorrhagia, postmenopausal bleeding, suspected pathology of the uterine cavity (fibroid, polyp, or cancer of the uterine lining endometrium), uterine malformation, uterine synechia, as well as in the investigation of infertility, repeated abortions and to assist in the removal of an intrauterine device whose strings are not otherwise visible $^{(7-9)}$. In addition to avoiding general anesthesia, another advantage of $\mathrm{OH}$ is the sparing of the patient of many expenses such as hospital stay and operating room fees ${ }^{(8,10)}$. Nevertheless, the pain associated with $\mathrm{OH}$ remains a troublesome barrier for women, and the ideal regimen or combination of local or systemic anesthesia is still being investigated ${ }^{(11)}$

The nature of pain experienced at the time of $\mathrm{OH}$ is not completely understood, but many authors attribute the majority of the pain to mechanical cervical dilation necessary to access the uterine cavity during the procedure, as well as the distending agent ${ }^{(12,13)}$.

Several approaches have been suggested by different authors to control this pain. Some suggested regimens have included the oral administration of non-steroidal anti-inflammatory drugs (NSAIDs) at the time of hysteroscopy ${ }^{(2)}$, and others have attempted local anesthesia to improve pain ${ }^{(14,15)}$. Tramadol (Ultram) is a synthetic codeine analogue, with central analgesic properties with effects similar to other opioids, such as morphine and codeine, acting on specific opioid receptors. Unlike traditional opioids such as morphine and oxycodone, tramadol's main mechanism of action is unknown, resulting in lower addictive potential and classification as schedule IV in the United States Drug Enforcement Agency (DEA) classification. As a result, tramadol is widely used in postoperative pain management in obstetrics and gynecology. Common adverse effects of tramadol include nausea, vomiting, headache, dizziness, gastric pain, anxiety, panic attacks and depression. Tramadol can be administered orally or parenterally before hysteroscopy. The oral route allows reducing the discomfort by avoiding injection, but some authors have reported it may have limited benefit compared with the parenteral route ${ }^{(16)}$.
Since the last major meta-analysis of the use of tramadol in $\mathrm{OH}^{(17)}$, our authors observed the publication of two major randomized controlled trials (RCTs) on this same topic ${ }^{(18,19)}$. As a result, in response to the new relative wealth of data, we aimed to systematically review all available data concerning the efficacy and safety of tramadol in relieving the pain of $\mathrm{OH}$.

\section{Materials and Methods}

We conducted this systematic review according to the Preferred Reporting Items for Systematic Reviews and Meta-analyses guidelines ${ }^{(20)}$, and performed all steps in strict accordance with the Cochrane handbook of systematic reviews of interventions ${ }^{(21)}$.

\section{Literature Search Strategy}

We conducted a detailed search using several electronic databases including ClinicalTrials.gov, MEDLINE, PubMed, SCOPUS, and the Cochrane Library. Our search protocol involved different combinations of these MeSH terms: (Tramadol OR Tramundin OR Biodalgic OR Jutadol OR Nobligan OR Prontofort OR Zytram OR Takadol OR Theradol OR Tiral OR Topalgic OR Tradol OR Tradonal OR Tralgiol OR "Trama AbZ" OR "Trama Dorsch" OR Biokanol OR Tramabeta OR Tramadin OR Tramadoc OR "Trama 1A Pharma" OR Trasedal OR Xymel OR Zamudol OR Zumalgic OR Zydol OR Tramadura OR Tramagetic OR Tramagit OR Tramake OR Tramal OR Tramex OR Adolonta OR Contramal OR Amadol OR Qdolo OR Ryzolt OR ConZip) AND (Hysteroscopy OR Hysteroscopies OR "Uterine Endoscopy" OR Uteroscopy OR Uteroscopies OR "Uterine Endoscopies" OR "Hysteroscopic Surgical Procedure" OR "Hysteroscopic Surgery" OR "Hysteroscopic Surgeries"). Studies were collected up to February $28^{\text {th }}, 2021$. We then manually reviewed all of the references of the originally located studies, as well as all of the references of the systematic reviews that have been previously published on this topic. These were all reviewed to search for any RCTs that could have been missed by our original search strategy.

\section{Eligibility Criteria and Study Selection}

Two independent authors screened the titles and abstracts of the identified articles to assess relevance to this meta-analysis. In case of disagreement, the full text was retrieved and reviewed independently by a senior author for a final decision. We included every RCT that we could locate that included a comparison of tramadol and placebo for reducing pain associated with $\mathrm{OH}$. We did not include any restriction as far as the age or race of the patients, the country of origin of the study, or the date that the study was published. We excluded the following four groups of studies: (1) studies not published in the English language, (2) studies that were based on conference posters, found in books, review articles, doctoral thesis, opinionated editorials, letters to the editor, non-randomized case series, and isolated case reports, (3) data that could not be considered to be reliably extracted, studies with overlapping sets of data, studies that 
had only the abstract available, and (4) studies that had animal participants. Duplicates were removed and retrieved references were screened in two steps: the first step was to screen titles/ abstracts for matching our inclusion criteria and the second step was to screen the full-text articles of eligible abstracts for eligibility for meta-analysis.

\section{Data Extraction}

Two independent authors extracted the relevant data from the included studies. The initial selected data included the patient's body mass index, indication for hysteroscopy, age, gestational parity, and the total duration of the hysteroscopy in minutes. The primary outcome that we extracted was the score assessed using a visual analog scale (VAS) associated with the hysteroscopy. We extracted data to measure this pain scale during three separate periods. These included pain that occurred during the procedure, immediately following the procedure, and lastly, half an hour after the conclusion of the procedure). We also extracted a secondary outcome: tramadol adverse effects, which include dizziness and vomiting in a form of number and percentage.

\section{Quality of Included Studies and Risk of Bias Assessment}

The risk of bias and quality of the eligible studies was assessed by two independent reviewers. We used the Cochrane Collaboration's tool for the assessment of the risk of bias ${ }^{(21)}$. Any discrepancies were solved through discussion and consensus between reviewers. The domains upon which the included articles were assessed were sequence generation (selection bias), allocation sequence concealment (selection bias), blinding of participants and personnel (performance bias), blinding of outcome assessment (detection bias), incomplete outcome data (attrition bias), selective outcome reporting (reporting bias) and other potential sources of bias. The authors' judgment was categorized as "Low risk", "High risk" or "Unclear risk" of bias.

\section{Data Synthesis}

In the statistical analysis, we used the Review Manager Software (RevMan version 5.3). Relative risk and $95 \%$ confidence intervals (CI) were used in our analysis. In dichotomous data, event and total were used to represent the data, and in continuous data, mean (M) and standard deviation (SD) were used. The missing SD was calculated from the standard error, $95 \% \mathrm{CI}$, or range according to Wan et al. (22). To test for statistical heterogeneity between trials, chi-square and $\mathrm{I}^{2}$ tests were employed; values of 0-40\%, 30-60\%, $50-90 \%$, and $75-100 \%$ represented low, moderate, substantial, and considerable heterogeneity respectively. A p-value of $\geq 0.1$ was set as the level of significant homogeneity.

\section{Results}

\section{Results of Literature Search}

Following our literature search and removal of duplications, there were 82 studies available for title and abstract screening. Seventeen studies were initially eligible for full-text screening.
Only six studies (738 patients) fulfilled our eligibility criteria, and five were included in our meta-analysis figure 1 illustrates the PRISMA flow diagram) ${ }^{(18,19,23-25)}$. The sixth study was not included in our analysis because it reported the outcomes in the form of median only, so we could not convert the data into means and SD values for meaningful comparison with the other included studies ${ }^{(26)}$. All included studies were double-blinded RCTs. The summary of baseline characteristics of enrolled patients is presented in Table 1 .

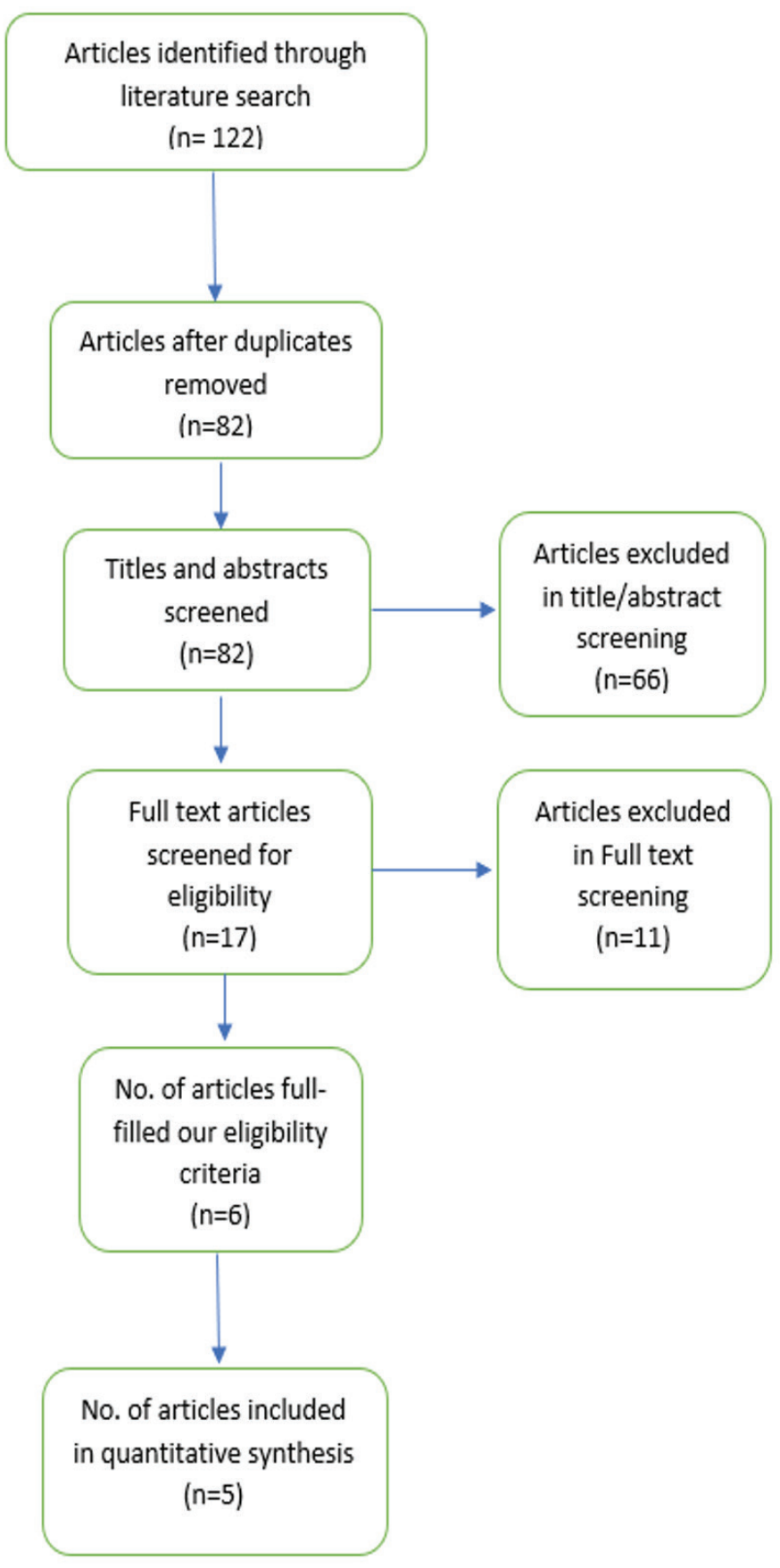

Figure 1. PRISMA flow diagram 
Table 1. Baseline characteristics of included studies

\begin{tabular}{|c|c|c|c|c|c|c|c|c|}
\hline 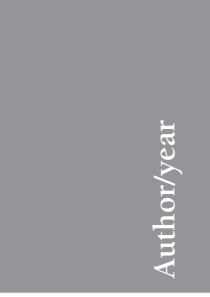 & $\begin{array}{l}\text { है } \\
\text { है } \\
\text { कू } \\
\text { ते } \\
\text { है }\end{array}$ & 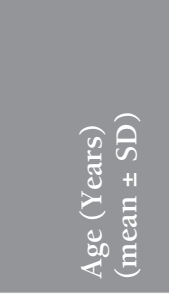 & 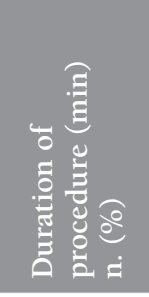 & 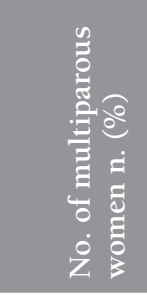 & $\begin{array}{l}\text { के } \\
+1 \\
\equiv \\
\Xi \\
\Xi \\
\sum_{\infty}^{E}\end{array}$ & \multicolumn{3}{|c|}{ Indication of hysteroscopy } \\
\hline $\begin{array}{l}\text { Bharathi et } \\
\text { al. }{ }^{(18)}\end{array}$ & Placebo & $45.4 \pm 8.4$ & $3.75 \pm 2.35$ & $47(94)$ & NA & $40(80)$ & NA & NA \\
\hline \multirow{2}{*}{ Floris et al. ${ }^{(23)}$} & Tramadol (100 mg/2 mL I.V) & $47.2 \pm 2.8$ & $1.63 \pm 0.16$ & $25(100)$ & NA & $10(40)$ & NA & NA \\
\hline & placebo & $44.3 \pm 2.5$ & $1.64 \pm 0.18$ & $25(100)$ & NA & $8(32)$ & NA & NA \\
\hline Hassan et al. ${ }^{(24)}$ & Tramadol (100 mg orally) & $29.25 \pm 6.39$ & $1.92 \pm 0.98$ & $25(35.7)$ & $25.77 \pm 4.37$ & $16(22.9)$ & $10(14.2)$ & $39(55.8)$ \\
\hline Hassan et al. ${ }^{(25)}$ & Placebo & $32.3 \pm 8.1$ & $2.1 \pm 1.1$ & NA & $28.8 \pm 2.8$ & $14(20)$ & $19(27)$ & $32(46)$ \\
\hline \multirow{2}{*}{ Samy et al. ${ }^{(19)}$} & Tramadol (50 mg orally) & $57.8 \pm 7.3$ & $3.3 \pm 1.7$ & NA & $27.9 \pm 3.4$ & NA & NA & NA \\
\hline & Placebo & $60.4 \pm 6.7$ & $3.1 \pm 1.1$ & NA & $29.1 \pm 3.4$ & NA & NA & NA \\
\hline \multirow{2}{*}{$\begin{array}{l}\text { Kadiroğulları } \\
\text { et al. }{ }^{(26)}\end{array}$} & Tramadol (100 mg orally) & $45 \pm 1.4$ & NA & NA & $27 \pm 2.8$ & $15(34)$ & NA & NA \\
\hline & Placebo & $44.08 \pm 1.3$ & NA & NA & $28.2 \pm 1.9$ & $19(43)$ & NA & NA \\
\hline
\end{tabular}

NA: Not available, n: Number, SD: Standard deviation

\section{Results of Quality Assessment}

According to the Cochrane risk of bias assessment tool ${ }^{(21)}$, the overall risk of bias of the included studies was low. All included studies were at low risk of random sequence generation, blinding of participants and personnel, incomplete data, and selective reporting. However, three studies were unclear in the term of allocation concealment ${ }^{(23,25,26)}$. Also, three studies were unclear in the blinding of outcome assessment ${ }^{(19,23,25)}$. Figure 2 illustrates the results of risk of bias assessment for each domain in included studies.

\section{Results of Outcomes}

\section{Pain Score}

\section{Pain During The Procedure}

All studies ${ }^{(18,19,23-25)}$ reported pain score outcomes during the procedure using VAS scores. The analysis significantly favored the tramadol group over the placebo group $[\mathrm{MD}=-1.27,95 \%$ CI: $(-1.66,-0.88) ; \mathrm{p}<0.001)$. Data were homogenous $(\mathrm{p}=0.66$, $\left.\mathrm{I}^{2}=0 \%\right)$. A forest plot of these data is shown in Figure 3.

\section{Pain Immediately After The Procedure}

All studies ${ }^{(18,19,23-25)}$ reported pain score outcomes after the procedure using VAS scores. The analysis significantly favored the tramadol group over the placebo group $[\mathrm{MD}=-1.03,95 \%$ CI: $(-1.40,-0.67) ; p<0.001]$. Data were homogenous $(\mathrm{p}=0.999$,

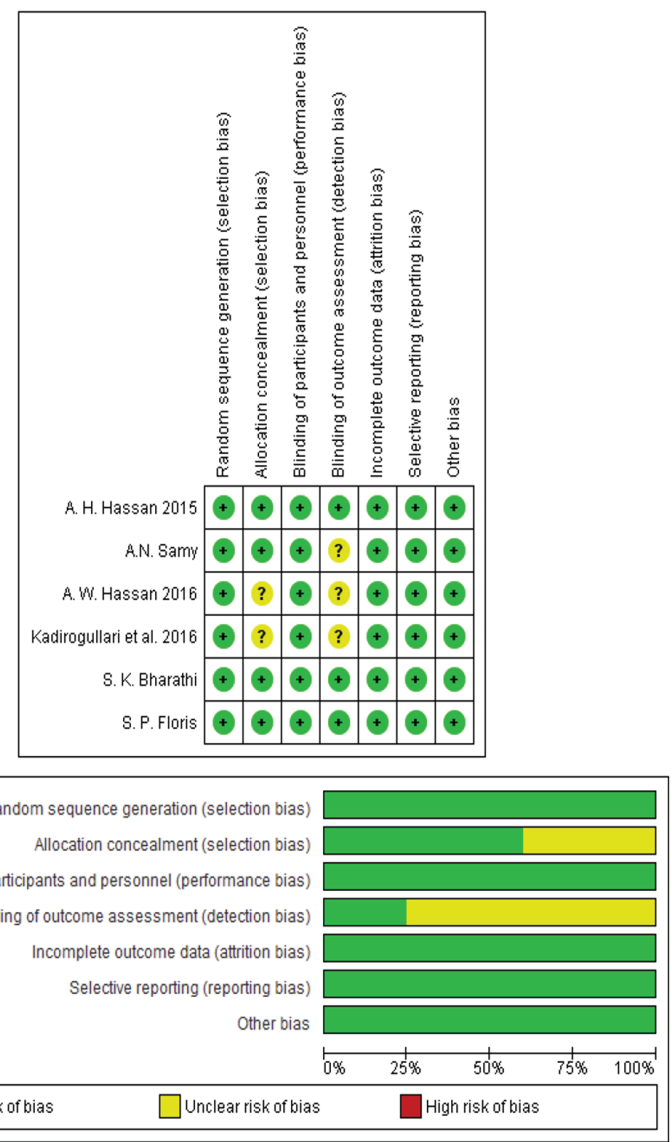

Figure 2. Risk of bias assessment 


\begin{tabular}{|c|c|c|c|c|c|c|c|c|c|c|}
\hline \multirow[b]{2}{*}{ Study or Subgroup } & \multicolumn{3}{|c|}{ Tramadol } & \multicolumn{3}{|c|}{ Placebo } & \multicolumn{2}{|r|}{ Mean Difference } & \multirow{2}{*}{\multicolumn{2}{|c|}{$\begin{array}{l}\text { Mean Difference } \\
\text { IV, Fixed, } 95 \% \mathrm{Cl}\end{array}$}} \\
\hline & Mean & SD & Total & Mean & SD & Total & Weight & IV, Fixed, 95\% Cl & & \\
\hline S. P. Floris & 4.53 & 2.15 & 25 & 6.5 & 3.05 & 25 & $7.1 \%$ & $-1.97[-3.43,-0.51]$ & - & \\
\hline S. K. Bharathi & 7 & 2.22 & 48 & 8 & 0.74 & 50 & $34.6 \%$ & $-1.00[-1.66,-0.34]$ & -1 & \\
\hline A.N. Samy & 4.7 & 2.1 & 52 & 5.8 & 2.3 & 52 & $21.1 \%$ & $-1.10[-1.95,-0.25]$ & - & \\
\hline A. W. Hassan 2016 & 5 & 5.9 & 70 & 6 & 5.9 & 70 & $3.9 \%$ & $-1.00[-2.95,0.95]$ & & \\
\hline A. H. Hassan 2015 & 4.37 & 1.77 & 70 & 5.92 & 2.26 & 70 & $33.4 \%$ & $-1.55[-2.22,-0.88]$ & -1 & \\
\hline Total $(95 \% \mathrm{Cl})$ & & & 265 & & & 267 & $100.0 \%$ & $-1.27[-1.66,-0.88]$ & $\checkmark$ & \\
\hline $\begin{array}{l}\text { Heterogeneity: } \mathrm{Chi}^{2}= \\
\text { Test for overall effect }\end{array}$ & $\begin{array}{l}2.42, \mathrm{df} \\
Z=6.42\end{array}$ & $\begin{array}{l}=4(P \\
(P<0\end{array}$ & $\begin{array}{l}=0.66) \\
.00001\end{array}$ & $i^{2}=0$ & & & & & $\begin{array}{lll}1 & 1 \\
-10 & -5 & 0 \\
\text { Favours } & \text { [Tramadol] }\end{array}$ & \begin{tabular}{|cc} 
& 1 \\
5 & 10 \\
Favours [Placebo]
\end{tabular} \\
\hline
\end{tabular}

Figure 3. Forest plot of visual analog scale pain outcomes during the procedure

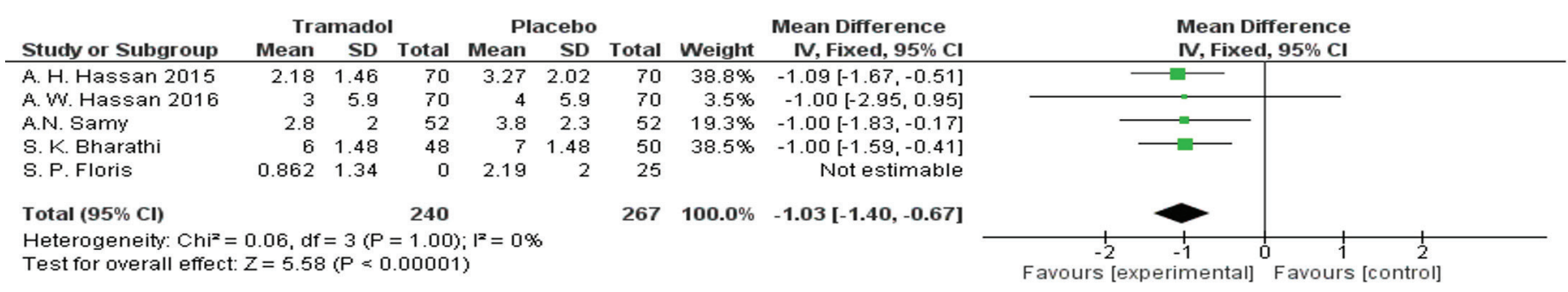

Figure 4. Forest plot of visual analog scale pain outcomes immediately after the procedure

$\left.\mathrm{I}^{2}=0 \%\right)$. A forest plot of these data I presented in Figure 4.

\section{Pain Half an Hour After the Procedure}

All studies ${ }^{(18,19,23-25)}$ reported pain score outcomes 30 minutes after the procedure using VAS scores except Floris et al. ${ }^{(23)}$. The analysis significantly favored the tramadol group over the placebo group [MD=-0.74, 95\% CI: $(-1.06,-0.41) ; \mathrm{p}<0.001]$. Data were homogenous $\left(\mathrm{p}=0.19, \mathrm{I}^{2}=36 \%\right)$. A forest plot of this data is shown in Figure 5.

\section{Time Until the Patient Was Pain-free}

Hassan et al. ${ }^{(24)}$ and Samy et al. ${ }^{(19)}$ reported the elapsed time until the patient was pain-free. The analysis significantly favored the tramadol group over the placebo group [MD=-8.65, 95\% CI: $(-12.41,-4.89) ; \mathrm{p}<0.001]$. Data were homogenous $(\mathrm{p}=0.43$, $\mathrm{I}^{2}=0 \%$ ). A forest plot of these data is presented in Figure 6 .

\section{Adverse Effects}

\section{Dizziness}

Samy et al. ${ }^{(19)}$ and Bharathi et al. ${ }^{(18)}$ reported dizziness outcomes. There was no significant difference between tramadol and placebo groups $[\mathrm{RR}=1.88,95 \% \mathrm{CI}:(0.79,4.47) ; \mathrm{p}=0.16]$. Data were homogenous $\left(\mathrm{p}=0.81, \mathrm{I}^{2}=0 \%\right)$. A forest plot of these data is shown in Figure 7.

\section{Vomiting}

Samy et al. ${ }^{(19)}$ and Floris et al. ${ }^{(23)}$ reported vomiting outcomes. There was no significant difference between tramadol and placebo groups [RR=1.80, 95\% CI: $(0.40,8.18) ; p=0.45]$. Data were homogenous $\left(\mathrm{p}=0.71, \mathrm{I}^{2}=0 \%\right)$. A forest plot of these data is presented in Figure 8.

\section{Discussion}

Our analysis found that the use of tramadol before the hysteroscopy procedure could significantly reduce pain scores (VAS score) during and 30 minutes after the procedure. We also found that the time until the patient was completely pain-free was significantly shorter in the tramadol group when compared with the placebo. As for safety, our review analyzed two adverse effects, dizziness and vomiting, and we found that there was no significant difference between tramadol and placebo groups. A major impetus for this review was the review two years ago performed by Mattar et al. ${ }^{(17)}$ in 2019 that first showed an improvement in pain scores with the use of tramadol during $\mathrm{OH}$. This review also found that the use of tramadol resulted in no significant adverse effects. These results were similar to those of our analysis. This earlier analysis included only four studies $^{(23-26)}$. Our study was able to include six studies, allowing a much larger sample size because more data have become available $e^{(18,19,23-25)}$. The previous analysis analyzed only patients of reproductive and perimenopausal age. Our analysis has additionally been able to assess patients in the post-menopausal period to ensure diverse data covering the entire range of patients undergoing hysteroscopy. Hence, we consider that this analysis may be seen as more comprehensive. In addition, this analysis assessed new outcomes (time to until the patient is pain-free) and a new adverse effect (dizziness).

A range of pharmacologic interventions, such as local anesthesia, oral and intravenous opioids, NSAIDs, misoprostol, lidocaineprilocaine cream, dinoprostone, and buprenorphine) and non-pharmacologic interventions [including transcutaneous electrical nerve stimulation (TENS), bladder distension, music and warm saline] have been used to reduce the pain associated 


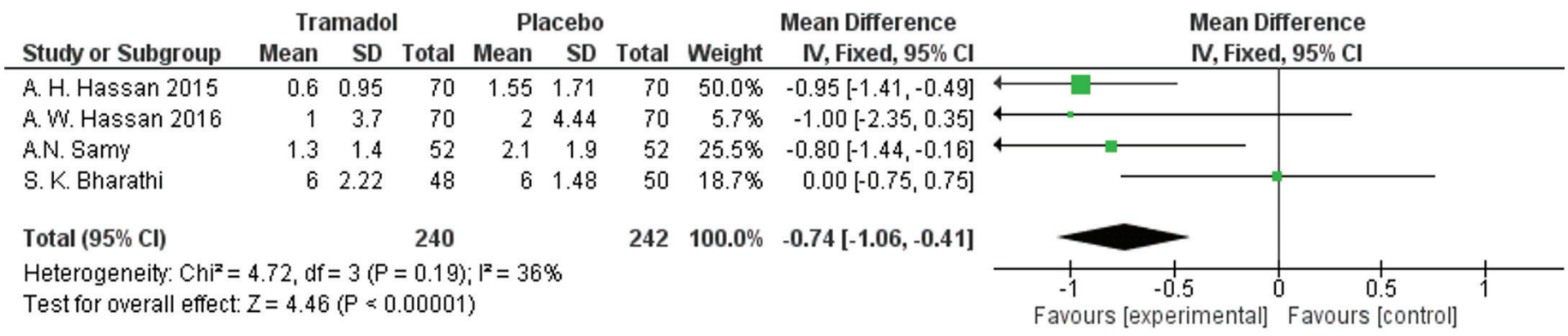

Figure 5. Forest plot of visual analog scale pain outcomes 30 minutes after the procedure

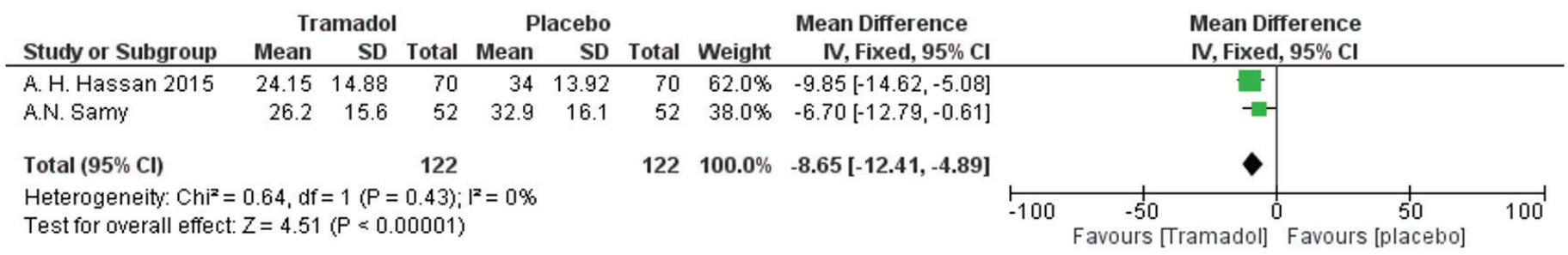

Figure 6. Forest plot of elapsed time until the patient is pain-free

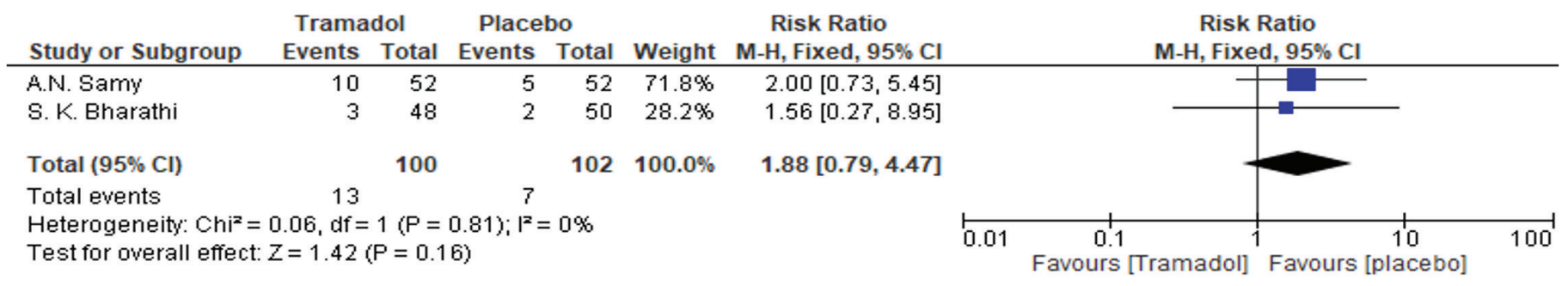

Figure 7. Forest plot of the incidence of patient-reported dizziness as an adverse effect

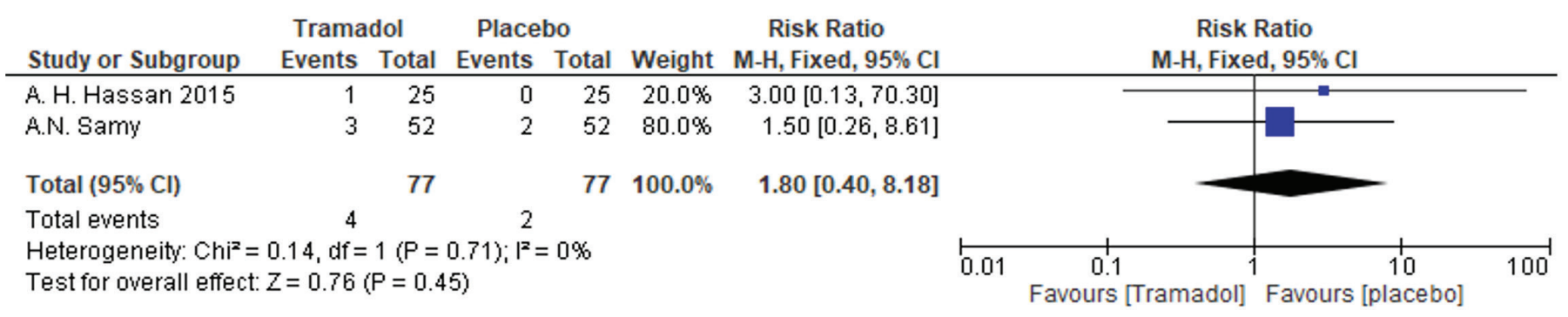

Figure 8. Forest plot of the incidence of vomiting as an adverse effect

with the hysteroscopy procedure. A recent review and metaanalysis evaluated these interventions to detect the highestranked intervention that could be applied. The review concluded that the combination of misoprostol and local anesthesia was the most effective pharmacologic intervention. As for nonpharmacologic interventions, TENS and bladder distension were effective but further investigations were recommended ${ }^{(27)}$. Another recent review compared the efficacy of different types and routes of administration of local anesthesia (topical, paracervical, intracervical, topical and transcervical, and intracornual), and found that any route of administration could be considered in pain management during $\mathrm{OH}$. It also found that mepivacaine and bupivacaine were the only local anesthetics that seemed to significantly reduce the pain score after the procedure ${ }^{(28)}$. Nevertheless, Cooper et al. ${ }^{(29)}$ concluded that local anesthesia via the intracervical route was the best in pain management during $\mathrm{OH}$ compared with different routes of local anesthesia administration. 
A review by Ahmad et al. ${ }^{(30)}$ assessed the efficacy of various analgesics used to reduce the pain associated with the hysteroscopy procedure. The authors found that neither opioids nor NSAIDs significantly reduced the pain score during the procedure and 30 min after the procedure.

As for lidocaine, De silva et al. ${ }^{(28)}$ concluded that it could relieve the pain only during $\mathrm{OH}$, but there was no significant reduction in the pain after the procedure. These findings were similar to an RCT by Samy et al. ${ }^{(19)}$ who found the superiority of lidocaine to placebo in pain control during and $10 \mathrm{~min}$ after the procedure, but there was no significant difference $30 \mathrm{~min}$ after the procedure.

Mohammadi et al. ${ }^{(31)}$ reported that rectal diclofenac was better than intrauterine lidocaine in pain control during $\mathrm{OH}$; however, no significant difference in the pain score was found between the two groups. Similarly, El-Gamal found that oral diclofenac was more effective than lidocaine in pain management during $\mathrm{OH}^{(32)}$. However, Senturk and Guraslan ${ }^{(33)}$ found that intrauterine lidocaine was superior to rectal indomethacin in pain relief while performing $\mathrm{OH}$.

Prostaglandins are another medication proposed to reduce discomfort in hysteroscopic procedures ${ }^{(29)}$. They act by ripening the cervix to facilitate easy dilatation ${ }^{(34)}$. A review by Cooper et al. ${ }^{(29)}$ assessed their efficacy in the pain relief associated with hysteroscopy compared with placebo in both premenopausal and postmenopausal women. It concluded that there was no evidence that the use of either misoprostol or mifepristone could reduce the pain associated with the procedure.

In a comparison with other analgesics, Samy et al. ${ }^{(19)}$ found that there was no significant difference between tramadol and lidocaine in either the reduction of the pain scores or time until the patient was pain-free. Hassan et al. ${ }^{(24,25)}$ found that there was no significant difference between tramadol and celecoxib in the reduction of the pain scores during and after $\mathrm{OH}$, but found celecoxib had fewer adverse effects.

\section{Study Strengths and Limitations}

The main strength of our analysis is the inclusion of doubleblinded controlled trials with a low risk of bias. Also, the data of the included studies are homogenous. The main limitation is the low number of included studies.

Further RCTs are needed to establish the safety and efficacy of tramadol in postmenopausal women undergoing $\mathrm{OH}$, although our initial data here are promising. The comparison of the different tramadol doses and different routes of administration would also give valuable insight into the most efficacious way to administer tramadol, and may maximize pain relief.

\section{Conclusion}

This analysis has found that tramadol can be used effectively and safely in the management of pain in $\mathrm{OH}$.

\section{Ethics}

Peer-review: Externally peer-reviewed.

\section{Authorship Contributions}

Surgical and Medical Practices: H.M., G.J.M., K.W., A.M., A.K., S.R., G.B., H.U., J.P., A.A., K.S., M.A.S., Concept: H.M., G.J.M., K.W., A.M., A.K., S.R., G.B., H.U., J.P., A.A., K.S., M.A.S., Design: H.M., G.J.M., K.W., A.M., A.K., S.R., G.B., H.U., J.P., A.A., K.S., M.A.S., Data Collection or Processing: H.M., G.J.M., K.W., A.M., A.K., S.R., G.B., H.U., J.P., A.A., K.S., M.A.S., Analysis or Interpretation: H.M., G.J.M., K.W., A.M., A.K., S.R., G.B., H.U., J.P., A.A., K.S., M.A.S., Literature Search: H.M., G.J.M., K.W., A.M., A.K., S.R., G.B., H.U., J.P., A.A., K.S., M.A.S., Writing: H.M., G.J.M., K.W., A.M., A.K., S.R., G.B., H.U., J.P., A.A., K.S., M.A.S.

Conflict of Interest: No conflict of interest was declared by the authors.

Financial Disclosure: The authors declared that this study received no financial support.

\section{References}

1. Gimpelson RJ, Whalen TR. Hysteroscopy as gold standard for evaluation of abnormal uterine bleeding. Am J Obstet Gynecol 1995;173:1637.

2. Nagele F, Lockwoodb G, Magos AL. Randomised placebo controlled trial of mefenamic acid for pr:emedication at outpatient hysteroscopy: a pilot study. Br J Obstet Gynaecol 1997;104:842-4.

3. Raju KS. Should outpatient hysteroscopy replace conventional diagnostic dilatation and curettage in gynecologic practice? J Gynecol Surg 1992;8:225-30.

4. Valle RF. Office hysteroscopy. Clin Obstet Gynecol 1999;42:27689.

5. Kuroda K, Kitade M, Kikuchi I, Kumakiri J, Matsuoka S, Tokita S, et al. A new instrument: a flexible hysteroscope with narrow band imaging system - Optical quality comparison between a flexible and a rigid hysteroscope. Minim Invasive Ther Allied Technol 2011;20:263-6.

6. Unfried G, Wieser F, Albrecht A, Kaider A, Nagele, F. Flexible versus rigid endoscopes for outpatient hysteroscopy: a prospective randomized clinical trial. Hum Reprod 2001;16:168-71.

7. Kayatas S, Meseci E, Tosun OA, Arinkan SA, Uygur L, Api M. Experience of hysteroscopy indications and complications in 5, 474 cases. Clin Exp Obstet Gynecol 2014;41:451-4.

8. Taylor PJ, Hamou JE. Hysteroscopy. J Reprod Med Obstet Gynecol 1983;28:359-89.

9. Topsoee MF, Ibfelt EH, Settnes A. The Danish hysterectomy and hysteroscopy database. Clin Epidemiol 2016;8:515-20.

10. Di Spiezio Sardo A, Calagna G, Santangelo F, Zizolfi B, Tanos $\mathrm{V}$, Perino A, et al.. The role of hysteroscopy in the diagnosis and treatment of adenomyosis. BioMed Res Int 2017:1-7.

11. De Iaco P, Marabini A, Stefanetti M, Del Vecchio C, Bovicelli L. Acceptability and pain of outpatient hysteroscopy. J Am Assoc Gynecol Laparosc 2000;7:71-5.

12. Campo R, Molinas CR, Rombauts L, Mestdagh G, Lauwers M, Braekmans $\mathrm{P}$, et al. Prospective multicentre randomized controlled trial to evaluate factors influencing the success rate of office diagnostic hysteroscopy. Hum Reprod 2005;20:258-63.

13. De Angelis C, Santoro G, Re ME, Nofroni I. Office hysteroscopy and compliance: Mini-hysteroscopy versus traditional hysteroscopy in a randomized trial. Hum Reprod 2003;18:2441-5. 
14. Cooper AM, Khan KS, Clark TJ. Local anaesthesia for pain control during outpatient hysteroscopy: Systematic review and metaanalysis. BMJ 2010;340:c1130. doi: 10.1136/bmj.cl130.

15. Wong AYK, Wong KS, Tang LCH. Stepwise pain score analysis of the effect of local lignocaine on outpatient hysteroscopy: a randomized, double-blind, placebo-controlled trial. Fertil Steril 2000;73:1234-7.

16. Lewis KS, Han NH. Tramadol: A new centrally acting analgesic. Am J Health Syst Pharm1997;54:643-52.

17. Mattar OM, Abdalla AR, Shehata MSA, Ali AS, Sinokrot M, Abdelazeim BA, et al. Efficacy and safety of tramadol in pain relief during diagnostic outpatient hysteroscopy: systematic review and meta-analysis of randomized controlled trials. Fertil Steril 2019;111:547-52.

18. Bharathi S, Maurya DK, Keepanasseril A, Kubera NS. Efficacy and safety of Tramadol as an analgesic in women undergoing vaginoscopic hysteroscopy: a randomized placebo-controlled trial. J Obstet Gynaecol 2020;40:678-83.

19. Samy A, Nabil H, Abdelhakim AM, Mahy ME, Abdel-Latif AA, Metwally AA. Pain management during diagnostic office hysteroscopy in postmenopausal women: a randomized study. Climacteric 2020;23:397-403.

20. Moher D, Liberati A, Tetzlaff J, Altman DG. Preferred reporting items for systematic reviews and meta-analyses: The PRISMA statement. PLoS Med 2009;6:e1000097. doi: 10.1371/journal.pmed.1000097.

21. Higgins JPT, Green S. Cochrane handbook for systematic reviews of interventions version 5.1.0 [updated March 2011]. New Jersey: John \& Wiley Sons, 2011.

22. Wan X, Wang W, Liu J, Tong T. Estimating the sample mean and standard deviation from the sample size, median, range and/or interquartile range. BMC Med Res Methodol 2014;14:135.

23. Floris S, Piras B, Orrù M, Silvetti E, Tusconi A, Melis F, et al. Efficacy of intravenous tramadol treatment for reducing pain during office diagnostic hysteroscopy. Fertil Steril 2007;87:147-51.

24. Hassan A, Wahba A, Haggag H. Tramadol versus Celecoxib for reducing pain associated with outpatient hysteroscopy: A randomized double-blind placebo-controlled trial. Hum Reprod 2016;31:60-6.
25. Hassan, A, Haggag, H. Role of oral tramadol $50 \mathrm{mg}$ in reducing pain associated with outpatient hysteroscopy: A randomised double-blind placebo-controlled trial. Aust N Z J Obstet Gynaecol 2016;56:102-6.

26. Kadiroğulları P, Seçkin KD, Yücel B, Çetin BA, Barut SA, Yıldırım G. Analgesic efficiency of tramadol administered prior to hysteroscopy procedure. Gynecol Obstet Reprod Med 2016;22:152-5.

27. Ghamry NK, Samy A, Abdelhakim AM, Elgebaly A, Ibrahim S, Ahmed AA, et al. Evaluation and ranking of different interventions for pain relief during outpatient hysteroscopy: A systematic review and network meta-analysis. J Obstet Gynaecol Res 2020;46:807-27.

28. De Silva PM, Carnegy A, Smith PP, Clark TJ. Local anaesthesia for office hysteroscopy: A systematic review meta-analysis. Eur J Obstet Gynecol Reprod Biol 2020;252:70-81.

29. Cooper NAM, Smith P, Khan KS. Does cervical preparation before outpatient hysteroscopy reduce women's pain experience? A systematic review. BJOG 2011;118:1292-301.

30. Ahmad G, Saluja S, O’Flynn H, Sorrentino A, Leach D, Watson A. Pain relief for outpatient hysteroscopy. Cochrane Database Syst Rev 2017;10.:CD007710 doi: 10.1002/14651858.CD007710.pub2.

31. Mohammadi SS, Abdi M, Movafegh A. Comparing transcervical intrauterine lidocaine instillation with rectal diclofenac for pain relief during outpatient hysteroscopy: a randomized controlled trial. Oman Med J 2015;30:157-61.

32. El-gamal HH, Elsayed A, Elbohoty H, Elsayed M. Lidocaine infusion on hysteroscopic media versus oral diclofenac for pain relief during outpatient hysteroscopy: a randomized controlled trial. Egypt J Hosp Med 2017;69:2143-8.

33. Senturk MB, Guraslan H. The effect of intrauterine lidocaine and rectal indomethacin on pain during office vaginoscopic hysteroscopy : randomized double-blind controlled study. gynecol obstet invest. 2016;81:280-4.

34. Pierce S, Bakker R, Myers DA, Edwards RK. Clinical insights for cervical ripening and labor induction using prostaglandins. AJP Rep 2018;8:e307-14. doi: 10.1055/s-0038-1675351. 